\title{
Lack of Association between CYP1A1 M2 and M4 Polymorphisms and Breast Carcinoma in Jordanian Women: a Case-Control Study
}

\author{
Iman Amrani ${ }^{1 *}$, Nailya Bulatova², Abdalla Awidi ${ }^{3}$, Al-Motassem Yousef ${ }^{2}$, Jamal \\ Masad Melhem ${ }^{4}$, Mahmoud Al-Masri ${ }^{5}$, Laila Abu Tahoun ${ }^{6}$
}

\begin{abstract}
Background: CYP1A1 is a candidate gene for low-penetrance breast cancer susceptibility, as it plays an important role in the metabolism of carcinogens and estrogens. Purpose: The objective of this study was to assess the association between $M 2(A 2455 G$, Ile462 Val $)$ and $M 4(C 2453 A$, Thr461Asn) polymorphisms in CYP1A1 and breast cancer risk among Jordanian women and in subgroups stratified by menopausal status and smoking history. Materials and Methods: Blood samples were collected from 112 breast cancer female patients and 115 age-matched controls who underwent breast cancer screening with imaging and showed negative results (BIRADS I or BI-RADS II). Genotyping was performed using the PCR-RFLP technique. Results: No statistically significant overall association was found between breast cancer risk and CYP1A1 M2 genotypes ( $p=0.55$; $\mathrm{OR}=0.77 ; 95 \% \mathrm{CI}=0.32-1.83)$ nor with the $M 4$ polymorphism $(p=0.95 ; \mathrm{OR}=0.95 ; 95 \% \mathrm{CI}=0.51-1.88)$. Analysis of subgroups defined by menopausal status or smoking history also revealed no association with these polymorphisms. Furthermore, the four identified haplotypes (AC; AA; GC and GA) were equally distributed among cases and controls, and haplotype analysis showed a strong linkage disequilibrium of both studied loci in either cases or controls $\left(D^{\prime}=1\right)$. Conclusions: Based on the study results, CYP1A1 M2 and M4 polymorphisms do not seem to play a major role in breast cancer risk among Jordanian females.
\end{abstract}

Keywords: CYP1A1, breast cancer, genotype, genetic polymorphism, SNP, Jordanian women, menopause, smoking.

Asian Pac J Cancer Prev, 17 (1), 387-393

\section{Introduction}

Breast cancer is the most common female malignancy worldwide. According to the latest statistics in 2010, breast cancer ranked first among cancers in Jordanian women accounting for $37.4 \%$ of all female cancers (Tarawneh et al., 2010). Breast cancer is both genetically and histopathologically heterogeneous and the mechanisms underlying breast cancer development remain poorly understood (Stuckey, 2011). Genetic studies have identified and confirmed four rare high-penetrance genes (BRCAl, BRCA2, TP53 and PTEN), four rare moderate-penetrance genes (CHEK2, ATM, BRIP1 and PALB2), and more than 20 common low-penetrance variants in 19 genes or loci that contribute to a woman's risk of breast cancer (Zhang et al., 2011; Huo et al., 2012). Low penetrance genes pose a low risk at the individual level but are more common in general population. Modulated by environmental exposure and lifestyle factors, these genes account for most sporadic breast cancer cases and are likely to explain the majority (90-95\%) of all breast cancer cases (Weber and Nathanson,
2000). CYP1Al is a candidate gene for low-penetrance breast cancer susceptibility because it plays a dual role, both in the phase I metabolism of carcinogens such as polyaromatic hydrocarbons (PAHs) (Shimada and FujiiKuriyama, 2004; Hodek et al., 2013) and in the oxidative metabolism of estrogens (Tsuchiya et al., 2005). The reactive intermediates resulting from these reactions may bind to DNA and form DNA adducts that may eventually produce mutations and trigger carcinogenesis (Firozi et al., 2002; Henkler et al., 2012). PAHs have been found to cause mammary tumors in rodents (Cavalieri et al., 1988) and estrogen is a known causal factor in breast cancer (Clemons and Goss, 2001; Tworoger et al., 2014). Catechol metabolites of estrogen may be causal as well. In humans, cytochrome P450 (CYP) 1A1 is responsible for extrahepatic 2-hydroxyaltion of estradiol (Spink et al., 1992). The resulting metabolite is devoid of estrogenic activity and the 2-methoxy derivatives are shown to possess anti-proliferative and anti-carcinogenic properties (Zhu and Conney, 1998). CYPlAl gene is located on chromosome 15q22-q24; it spans 5,987 base pairs;

${ }^{1}$ Department of Pharmacy, Faculty of Medicine, University of Batna Algeria, ${ }^{2}$ Department of Biopharmaceutics and Clinical Pharmacy. Faculty of Pharmacy, The University of Jordan, ${ }^{3}$ Department of Hematology and Oncology, ${ }^{4}$ Department of Surgery, The University of Jordan Hospital, ${ }^{5}$ Department of Surgical Oncology, ${ }^{6}$ Department of Radiology, King Hussein Cancer Center, Amman, Jordan*For correspondence: im.amrani@univ-batna.dz. 
comprises seven exons and six introns and encodes for a 512 amino acid protein (Kawajiri et al, 1986). CYP1A1 is highly polymorphic in humans. Four polymorphisms have been extensively studied and differences in the distribution of these polymorphisms among the different ethnicities and populations have been reported (Cosma, et al., 1993). The $M 1$ polymorphism (T3801C) is located in the 3 '-noncoding region giving rise to a $M s p I$ restriction site. The $M 2$ polymorphism is the replacement in position 2455 , on the exon 7 , of an adenine (A) by a guanine (G). This leads to the replacement of isoleucine (Ile) by valine (Val) on amino acid 462, in the heme binding region of the cytochrome $\mathrm{P} 450$ (Giri et al., 2012). The polymorphism M3 (T3205C) is the creation of another site of restriction $\mathrm{MspI}$ in the 3'-non-coding region and is specific of African-Americans. The polymorphism $M 4$ has not been studied extensively. It is located in position 2453, adjacent to the $M 2$ polymorphism. The $M 4$ polymorphism corresponds to the substitution of a cytosine (C) by an adenine (A) which leads to the loss of restriction site BsaI and is translated in the protein sequence by a replacement of a threonine (Thr) by aspargine (Asn) on the codon 461 (Sergentanis and Economopoulos, 2009). It is conceivable that the change in the protein sequence associated with $M 2$ and M4 polymorphisms could result in change in the enzyme activity (Cosma et al., 1993; Crofts et al., 1994). Functional significance of the different $C Y P 1 A l$ genotypes has been studied with inconclusive results. One study has found an increased inducibility of mRNA and 3 fold increase in enzyme activity associated with the $462 \mathrm{Val}$ variant allele (Crofts et al., 1994). This latter has also been found to increase lymphocyte CYP1Al enzyme activity in two other studies (Cosma et al., 1993; Kiyohara et al., 1996). However, several studies showed no change in enzyme function (Zhang et al., 1996; Persson et al., 1997)

CYPlAl polymorphisms and breast cancer association studies have raised conflicting results. A significant overall increased risk associated with 462 Val allele was observed among Asian (Chacko et al., 2005; Surekha et al., 2009; Saadatian et al., 2014), Caucasian (Zhang et al., 2004) and Mexican women (Martinez-Ramirez et al., 2013). Similarly, an increased risk in association with 461Asn variant allele was observed among French-Canadian Caucasian women (Krajinovic et al., 2001). However, a reduced risk was observed among Asian women in several studies (Miyoshi et al., 2002; Boyapati et al., 2005; Shin et al., 2007; Singh et al., 2007) and Caucasian women (Hefler et al., 2004). While all these studies have shown strong association between $C Y P 1 A 1$ polymorphisms and breast cancer risk, others have indicated no association (Rebbeck et al., 1994; Bailey et al., 1998; Basham et al., 2001; Sillanpaa el al., 2007; Kiruthiga et al., 2011; Petchkovskiy et al., 2014; Sun et al., 2015).

The aim of this work was to investigate the association between $M 2$ and $M 4$ polymorphisms of $C Y P 1 A 1$ and in Jordanian women. A secondary objective was to assess the association between $M 2$ and $M 4$ polymorphisms in CYPIAl and breast cancer risk in subgroups stratified by menopausal and smoking status.

\section{Materials and Methods}

\section{Subjects}

This multi-center case-control study was conducted in three major hospitals in Amman, the capital of Jordan: Jordan University Hospital (JUH), King Hussein Cancer Center (KHCC) and Jordan Hospital (JH). The study was approved by the Institutional Review Board (IRB) of these centers and written consent form was obtained from each participant. One hundred and twelve consecutive breast cancer female patients who were on their active followup were recruited from both Hematology/Oncology and Breast Surgery Clinics at JUH, as well as Breast Surgery Clinic at KHCC. All Jordanian patients with breast cancer were considered eligible (newly diagnosed cases, cases diagnosed years back and recurrent cases). Patients were age-matched with 115 female controls with no previous or present cancer history. All control subjects were selected during breast cancer screening programs and therefore have undergone mammography with or without breast ultrasound and had negative results (BIRADS I and BIRADS II). Controls were recruited from Breast Imaging Departments at JUH, KHCC, and JH. All blood samples were collected in the period between July 2010 and February 2011 in a 3ml EDTA anti-coagulant vacutainer tube under sterile conditions and were stored at $4{ }^{\circ} \mathrm{C}$ for one week at maximum or were frozen at $-20^{\circ} \mathrm{C}$ until DNA extraction was performed. Since all women approached except 25 agreed to participate in the study, the response rate was $90 \%$. During a face to face interview detailed information was obtained on demographic factors, reproductive and breastfeeding history, hormone use, age at breast cancer diagnosis if relevant, history of malignant diseases, dietary habits, physical activity, tobacco and alcohol use, and family history of breast cancer. Most of the participants had their waist and hip circumferences measured. The body mass index (BMI) was also recorded. Clinical history including the size of the tumor, presence of axillary lymph nodes, extent of metastasis (stage), histopathological type of the tumor, hormone receptor and HER-2 status was obtained from the patient file.

\section{Genotyping}

Genomic DNA specimens of patients and controls were extracted from buffy coat fractions (of fresh samples or samples stored at $4^{\circ} \mathrm{C}$ ) using Wizard Genomic DNA purification Kit (Promega, USA) following the manufacturer's protocol. For frozen samples (almost 20 samples), extraction from the whole blood was performed using NucleoSpin ${ }^{\circledR}$ Blood DNA purification Kit (Macherey Nagel, Germany) according to the manufacturer's protocol. DNA samples were stored at $-20^{\circ} \mathrm{C}$. DNA quality and quantity were assessed using spectrophotometry. For determination of $M 2$ polymorphism in CYPlA1 gene, a 204bp DNA fragment was amplified and restricted using PCR-RFLP based assay. The primers used were: M2F 5'-CTGTCTCCCTCTGGTTACAGGAAG3'(NC_000015.10:74720794-74720771) and M2R 5 ' - T TCCACCCGTTGCA GCA GGATAGCC-3' (NC_000015.10:74720591-74720615) (Cascorbi et al., 1996). The PCR reactions were performed in a PTC- 100 
Lack of Association between CYP1A1 M2 and M4 Polymorphisms and Breast Carcinoma in Jordanian Women: a Case-Control

Peltier thermal cycler (MJ Research Inc, USA) and target

DNA was amplified in a 50 $\mu 1$ of PCR mixture containing $2 \mu 1$ ( of genomic DNA, $0.3 \mu 1$ Taq polymerase, $1 \mu 1 \mathrm{dNTP}$ Mix, $10 \mu 15 x$ Taq polymerase green buffer, $1 \mu 1$ of each primer and $2 \mu 1 \mathrm{MgCl}_{2}$ and finally Nuclease free water up to $50 \mu 1$. The reaction mixture was initially denaturated at $94^{\circ} \mathrm{C}$ for 5 minutes followed by 40 cycles of $94^{\circ} \mathrm{C}$ for 30 seconds, $55^{\circ} \mathrm{C}$ for 1 minute and $72^{\circ} \mathrm{C}$ for 30 seconds. The reaction was completed by a final extension at $72^{\circ} \mathrm{C}$ for 5 minutes.

Digestion of PCR products (204 bp) with BsrDI (New England Biolabs, USA) at $65^{\circ} \mathrm{C}$ overnight, allowed the distinction between the fragments with wild-type allele (462Ile) by giving 2 fragments (149 bp and $55 \mathrm{bp}$ ) and the fragments with $462 \mathrm{Val}$ variant allele which remains undigested. M4 polymorphism could be determined from the same 204-bp fragment but using another restriction enzyme BsaI (New England Biolabs, USA) at $37^{\circ} \mathrm{C}$ overnight.

PCR products are digested into 2 fragments (139 bp and $65 \mathrm{bp}$ ) in case of wild-type allele (461Thr) and remain intact in case of 461Asn variant allele. The restricted products were analyzed by electrophoresis in $4 \%$ agarose gel containing ethidium bromide.

\section{Haplotype analysis}

The interaction between genetic polymorphism at the two loci was assessed by haplotype analysis. We analyzed haplotype frequencies of the two SNPs for breast cancer cases and compared them with those of controls. Haplotype frequencies were calculated using Golden Helix Tree ${ }^{\circledR}$ software and linkage disequilibrium was represented by D prime (D'). The Golden Helix software enables to estimate haplotype frequencies even with some missing data of one or both SNPs. Similar findings were obtained utilizing Multiallelic Interallelic Disequilibrium Analysis Software (University of Southampton, Highfield, Southampton, UK) (PMID: 16643648).

\section{Statistical analysis}

Statistical analysis was performed using the Statistical Package for Social Sciences (SPSS) software (SPSS Inc, USA) version 17.0.The association between CYP1A1 $M 2$ and $M 4$ polymorphisms and breast cancer risk was analyzed by calculating the crude odds ratios (OR) and $95 \%$ confidence intervals (95\% CI) using Chi-square

\section{Table 1. Selected Characteristics of Study Participants}

\begin{tabular}{|c|c|c|c|}
\hline Characteristics & $\begin{array}{l}\text { Cases }(\mathrm{N}=112) \\
\%^{\mathrm{a}} \text { or Mean } \pm \mathrm{Sd}\end{array}$ & $\begin{array}{c}\text { Controls }(\mathrm{N}=115) \\
\% \text { or Mean } \pm \text { Sd }\end{array}$ & $\begin{array}{c}P \text { Value: Cases } \\
\text { vs. Controls }\end{array}$ \\
\hline Age & $50.18 \pm 9.43$ & $48.03 \pm 8.21$ & 0.69 \\
\hline \multicolumn{4}{|l|}{ Educational level } \\
\hline Illiterate / elementary school & $18.7 \%$ & $6.1 \%$ & 0.009 \\
\hline Middle and High school & $27.7 \%$ & $38.3 \%$ & \\
\hline College or higher & $53.6 \%$ & $55.6 \%$ & \\
\hline \multicolumn{4}{|l|}{ Family monthly income } \\
\hline$<250 \mathrm{JD}^{\mathrm{b}}$ & $25 \%$ & $10.4 \%$ & 0.004 \\
\hline$>250 J D$ & $75 \%$ & $89.6 \%$ & \\
\hline \multicolumn{4}{|l|}{ Age at menarche } \\
\hline$<14$ & $55.5 \%$ & $66.7 \%$ & 0.76 \\
\hline$\geq 14$ & $44.5 \%$ & $33.3 \%$ & \\
\hline Regular period & $83 \%$ & $87 \%$ & 0.39 \\
\hline \multicolumn{4}{|l|}{ Menopausal status } \\
\hline Pre-menopausal & $67.9 \%$ & $63.5 \%$ & 0.88 \\
\hline Post-menopausal & $32.1 \%$ & $36.5 \%$ & \\
\hline Age at menopause & $44.44 \pm 9.07$ & $46.50 \pm 7.29$ & 0.30 \\
\hline Parous & $81.3 \%$ & $88.7 \%$ & 0.12 \\
\hline Age at first delivery (if parous) & $24.55 \pm 5.42$ & $23.35 \pm 5.14$ & 0.12 \\
\hline Breastfeeding & $77.7 \%$ & $83.4 \%$ & 0.27 \\
\hline Family history of breast cancer in the first degree relatives & $14.3 \%$ & $8.7 \%$ & 0.19 \\
\hline Direct hit to the breast & $17.9 \%$ & $8.7 \%$ & 0.001 \\
\hline \multicolumn{4}{|l|}{ Body size/ Lifestyle } \\
\hline $\mathrm{BMI}^{\mathrm{c}}$ & $28.65 \pm 5.41$ & $27.7 \pm 4.34$ & 0.15 \\
\hline WHR $^{\mathrm{d}}$ & $0.87 \pm 0.07$ & $0.85 \pm 0.10$ & 0.07 \\
\hline Ever smokers & $16.1 \%$ & $25.2 \%$ & 0.09 \\
\hline Number of pack-years (if smoker)e & $11.94 \pm 7.62$ & $9.52 \pm 8.87$ & 0.34 \\
\hline Physical activity in the last 5 years ${ }^{\mathrm{f}}$ & $40.2 \%$ & $62.6 \%$ & 0.001 \\
\hline Occasional alcohol intake & $6.3 \%$ & $11.3 \%$ & 0.179 \\
\hline High fat intake & $28.6 \%$ & $21.7 \%$ & 0.23 \\
\hline \multicolumn{4}{|l|}{ Exogenous hormone use } \\
\hline Ever used OCs ${ }^{g}$ & $44.6 \%$ & $49.6 \%$ & 0.458 \\
\hline Years of OCs use among users & $3.87 \pm 4.06$ & $2.90 \pm 3.59$ & 0.19 \\
\hline Years of HRT use among users & $2.80 \pm 5.04$ & $2.86 \pm 3.55$ & 0.98 \\
\hline
\end{tabular}

a: Valid percentage (There are missing data). b: Jordanian Dinar. c: Body mass index. d: waist to hip ratio. e: Number of pack years $=$ (number of cigarettes smoked per day x number of years smoked)/20 (1 pack contains 20 cigarettes). f: Physical activity in the last 5 years for controls and the 5 years prior to diagnosis for patients. g: Oral contraceptives, ever users are defined as women who used oral contraceptives for a duration equal or longer than 1 month. Only $p$ values for statistically significant differences are highlighted in bold 
test. Individual demographic and clinical factors were also examined for their relations to breast cancer using Chi-square test for categorical variables. The independentsample t-test was used for the continuous variables. Based on the data from previous studies, homozygotes for the CYPlAl 462Ile and 461Thr alleles were chosen as the reference categories in all separate analyses for these loci,. In a separate analysis, we also combined $462 \mathrm{ValVal}$ homozygotes with the 462Ile/Val heterozygotes and 461Asn/Asn homozygotes with 461Thr/Asn heterozygotes to increase the statistical power. Subgroup analysis was carried out separately for premenopausal and postmenopausal women and for the ever smokers and never smokers, respectively, to explore the potential modifying effect of non-genetic factors in the CYP1A1 M2 and M4breast carcinoma association. Women were considered to be postmenopausal if they had reported natural menopause determined as cessation of menstruation for at least 12 months, or had undergone bilateral oophorectomy. Women that were hysterectomized with intact ovaries (ovary) or for whom details of the operations were unknown were classified as postmenopausal if they were no longer menstruating and were older than 51 years or had used hormone replacement therapy. All the rest were classified as premenopausal (Sillanpaa et al., 2007). In breast cancer patients, criteria for menopausal status were applied to the age of diagnosis rather than to the age at the encounter, i.e., if the patient was still menstruating at the time of diagnosis, she was considered to be pre-menopausal. The patient was considered to be post-menopausal if she had experienced menopause before the date of diagnosis, and the cessation of menstruation has been for one year or more. Age at menopause was set to age at which menstrual periods ended or age of first use of hormone therapy, whichever came first. We also evaluated deviation from Hardy-Weinberg equilibrium for each SNP.

\section{Results}

The demographic characteristics and the putative risk factors of breast cancer investigated in this study are listed in Table 1. The mean age of breast cancer patients (50 years) did not statistically differ from that of controls (48 years, $p=0.69$ ). No significant difference was observed between cases and controls in terms of reproductive factors, exogenous hormone intake, smoking history, alcohol and dietary fat intake and lifestyle factors. However, controls had a higher family income $(p=0.004)$, a higher educational level $(p=0.009)$ and tended to be more physically active $(p=0.001)$ than patients. Moreover, women with breast carcinoma frequently reported direct hit (physical trauma) to the breast $(p=0.001)$. About onethird of patients in both groups were postmenopausal $(p=0.88)$. Most of the tumors were presented on the right breast $(55.4 \%)$, with invasive ductal histology $(75 \%)$, diagnosed at advanced stages (stage III-IV $=50.4 \%$ ), estrogen and progesterone receptor positive $(66 \%)$, and HER-2 negative (54.3\%).

The distribution of the $M 2$ and $M 4$ genotypes is shown in Table 2. All genotype frequencies were consistent with expectations from Hardy-Weinberg equilibrium in both: patients $\left(\chi^{2}=0.10 ; p=0.75\right)$ and controls $\left(\chi^{2}=0.087\right.$; $p=0.77$ ).

Association of M2 (Ile462Val) polymorphism with breast cancer risk

Frequencies of M2 462Ile and 462 Val alleles were 0.956 and 0.044 , respectively, among cases and 0.944 and 0.056 , respectively, among control subjects. Frequencies of M2 (462Ile/Ile), (462Ile/Val), and (462 Val/Val) for patients group $(0.910,0.893,0$ respectively) were not significantly different $(p=0.55)$ from those in the control group $(0.884,0.104$, and 0.008 respectively). When compared with M2 (462Ile/Ile) homozygous genotype carriers, carriers of the variant allele (M2 (462Ile/Val), and $M 2(462 \mathrm{Val} / \mathrm{Val}))$ had a non-significant $23 \%$ reduced risk of breast cancer $(\mathrm{OR}=0.77,95 \% \mathrm{CI} 0.32-1.83)$. When stratified by menopausal status, the distribution of $M 2$ genotypes in cases did not significantly vary from that of the control group (Table 3). Similarly, smoking history

Table 2. Association between CYPIAI $M 2$ and $M 4$ genotypes and breast cancer risk

\begin{tabular}{|c|c|c|c|c|}
\hline Genotype & $\begin{array}{l}\text { Cases } \\
\mathrm{n}(\%)\end{array}$ & $\begin{array}{c}\text { Controls } \\
\mathrm{n}(\%)\end{array}$ & $\begin{array}{c}\text { OR } \\
(95 \% \mathrm{CI})\end{array}$ & $P$ value \\
\hline \multicolumn{5}{|c|}{ CYP1A1 M2 (Ile462 Val) } \\
\hline Ile/Ile & $102(91.07)$ & $102(88.4)$ & 1.00 & 0.55 \\
\hline Ile/Val & $10(8.93)$ & $12(10.43)$ & - & \\
\hline $\mathrm{Val} / \mathrm{Val}$ & $0(0)$ & $1(0.87)$ & - & \\
\hline $\begin{array}{l}\text { Ile/Val, } \\
\quad+\text { Val/Val }\end{array}$ & $10(8.93)$ & $13(11.6)$ & $0.77(0.32-1$. & $.83)$ \\
\hline \multicolumn{5}{|c|}{ CYP1A1 M4 (Thr461Asn) } \\
\hline Thr/Thr & $90(80.4)$ & $92(80.0)$ & 1.00 & 0.95 \\
\hline Thr/Asn & $21(18.7)$ & $22(19.1)$ & - & \\
\hline Asn/Asn & $1(0.9)$ & $1(0.9)$ & - & \\
\hline $\begin{array}{l}\text { Thr/Asn, } \\
+ \text { Asn/Asn }\end{array}$ & $22(19.6)$ & $23(20.0)$ & $0.95(0.51-1$ & 1.88) \\
\hline
\end{tabular}

Table 3. Association Between CYP1A1 M2 and M4 Genotypes and Breast Cancer According to Menopausal Status

\begin{tabular}{|c|c|c|c|c|c|c|}
\hline \multirow[t]{2}{*}{ Genotype } & \multicolumn{2}{|c|}{$\begin{array}{c}\text { Premenopausal women } \\
\mathrm{n}(\%)\end{array}$} & \multirow[t]{2}{*}{ OR $(95 \% \mathrm{CI})$} & \multicolumn{2}{|c|}{$\begin{array}{c}\text { Postmenopausal women } \\
\mathrm{n}(\%)\end{array}$} & \multirow[t]{2}{*}{$\mathrm{OR}(95 \% \mathrm{CI})$} \\
\hline & Cases & Controls & & Cases & Controls & \\
\hline \multicolumn{7}{|l|}{ CYP1A1 (Ile462 Val) } \\
\hline Ile/Ile & $69(88.5)$ & $68(86.1)$ & $0.8(0.31-2.06)$ & $33(97.1)$ & $34(94.4)$ & $0.51(0.04-5.96)$ \\
\hline $\begin{array}{l}\text { Ile/Val+ Val/Val } \\
\text { CYPlAl(Thr461Asn) }\end{array}$ & $9(11.5)$ & $11(13.9)$ & & $1(2.9)$ & $2(5.6)$ & \\
\hline Thr/Thr & $63(80.8)$ & $66(83.5)$ & $1.21(0.53-2.74)$ & $27(79.4)$ & $26(72.2)$ & $0.67(0.22-2.04)$ \\
\hline$T h r / A s n+A s n / A s n$ & $15(19.2)$ & $13(16.5)$ & & $7(20.6)$ & $10(27.8)$ & \\
\hline
\end{tabular}


Lack of Association between CYP1A1 M2 and M4 Polymorphisms and Breast Carcinoma in Jordanian Women: a Case-Control Table 4. Association between CYP1A1 M2 and M4 Genotypes and Breast Cancer According to Smoking History

\begin{tabular}{|c|c|c|c|c|c|c|}
\hline \multirow[t]{2}{*}{ Genotype } & \multicolumn{2}{|c|}{ Never smokers n (\%) } & \multirow[t]{2}{*}{ OR $(95 \% \mathrm{CI})$} & \multicolumn{2}{|c|}{ Ever smokers n (\%) } & \multirow[t]{2}{*}{$\mathrm{OR}(95 \% \mathrm{CI})$} \\
\hline & Cases & Controls & & Cases & Controls & \\
\hline \multicolumn{7}{|l|}{ CYP1A1 (Ile462 Val) } \\
\hline Ile/Ile & $84(89.4)$ & $77(89.5)$ & $1.09(0.39-2.64)$ & $18(100)$ & $25(86.2)$ & 0 \\
\hline $\begin{array}{l}\mathrm{Ile} / \mathrm{Val}+\mathrm{Val} / \mathrm{Val} \\
\text { CYPlAl(Thr46lAsn) }\end{array}$ & $10(10.6)$ & $9(10.5)$ & & $0(0)$ & $4(13.8)$ & \\
\hline Thr/Thr & $74(78.7)$ & $71(82.6)$ & $1.28(0.61-2.69)$ & $16(88.9)$ & $21(72.4)$ & $0.33(0.06-1.76)$ \\
\hline Thr/Asn + Asn/Asn & $20(21.3)$ & $15(17.4)$ & & $2(11.1)$ & $8(27.6)$ & \\
\hline
\end{tabular}

Table 5. Association between CYP1A1 M2 / M4 Haplotypes and Breast Cancer Risk

\begin{tabular}{lcc}
\hline M2/M4 Haplotype & Cases & Control \\
\hline AC & 161 & 162 \\
AA & 18 & 19 \\
GC & 8 & 10 \\
GA & 1 & 1 \\
D' & 1 & 1 \\
r2 & 0.00535 & 0.00755 \\
\hline
\end{tabular}

had no impact on the relation of $M 2$ genotypes to breast cancer (Table 4).

Association of M4 (Thr461Asn) polymorphism with breast cancer risk:

Frequencies of 461Thr and 461Asn alleles were 0.897 and 0.103 , respectively, among cases and 0.896 and 0.104 , respectively, among control subjects. Among 112 breast cancer $80.4 \%, 18.7 \%$ and $0.9 \%$ were homozygote wild type (461Thr/Thr), heterozygote variant type (46Thr/Asn), and homozygotes variant type (461Asn/Asn) respectively. The distribution of these genotypes among the 115 controls was $80.0 \%, 19.1 \%$ and $0.9 \%$ respectively (Table 2). No statistically significant association was observed between the M4 (Thr461Asn) polymorphism and breast cancer risk $(p-$ value $=0.95, \mathrm{OR}=0.95 ; 95 \% \mathrm{CI}=0.51-1.88)$.

\section{CYP1Al haplotypes:}

Four different haplotypes appeared in our analysis. The most frequent haplotypes were AC (M2-A and M4-C) (cases: $85.7 \%$; controls: $84.1 \%$ ), followed by AA (cases: 9.8\%; controls: $9.8 \%$ ) and GC (cases: $4 \%$; controls: $5.5 \%$ ), while the rarest haplotype was GA (cases: $0.46 \%$; controls: $0.63 \%$ ) (Table 5). Our results indicated that the two loci $M 2$ and $M 4$ show relatively strong linkage disequilibrium (Lewontin's coefficient [D']) (Controls: D'=1; Cases: $\left.\mathrm{D}^{\prime}=1\right)$. None of the haplotypes was associated with breast cancer risk.

\section{Discussion}

In the current study, we investigated the relation between the two genotypes of CYP1A1, M2 (Ile462 Val) and M4 (Thr461Asn) and breast cancer risk in Jordanian female breast cancer patients compared to age-matched Jordanian female controls. To the best of our knowledge, this is the first study among Jordanian women assessing the interaction of both $M 2$ and $M 4$ genetic polymorphisms and breast cancer. This is also the first case-control study that used high accuracy in selecting control participants, as all of the controls have undergone mammography with or without breast ultrasound and have been proven to be breast malignancy-free. In addition, our study population is ethnically homogenous (Caucasians) which minimizes potential bias due to population stratification. The cooperation rate was $90 \%$. Thus, the cases can be viewed as representing unselected typical breast cancer patients from Amman area. However, it should be kept in mind that people who agree to participate in a study tend to be different from the remaining population regarding their demographic and lifestyle factors (Sillanpaa et al., 2007).

A wide ethnic variation in the distribution of $M 2$ and M4 polymorphisms was observed, with the $462 \mathrm{Val}$ variant allele being more common in Asians (30\%) (Huang et al., 1999) than in Caucasians (3-10\%) (Ambrosone et al., 1995; Zhang et al., 2004; Hefler et al., 2004). An intermediate value was observed among African-Americans (21\%) (Le Marchand et al., 2005). In the present study the frequency of the $462 \mathrm{Val}$ variant allele (4.46\% among cases and $5.67 \%$ among controls) is in accordance with that of Caucasians. Regarding the 461Asn variant allele there is little data available on its distribution in different ethnic populations. Our results show a higher frequency $(10.27 \%, 10.43 \%$ among cases and controls respectively) compared with the other studies in Caucasians (2.0 - 7.52\%) (Mrozikiewicz et al., 1997; Krajinovic et al., 2001; Sillanpaa et al., 2007).

The present study showed the lack of significant overall association between the M2 and M4 polymorphisms and breast cancer risk in Jordanian women. No association was also observed in premenopausal or postmenopausal subgroups. Our findings are in good agreement with several studies (Rebbeck et al., 1994; Bailey et al., 1998; Ishibe et al., 1998; Basham et al., 2001; Sillanpaa et al., 2007 and Kiruthiga et al., 2011; Sun et al., 2015). However, reduced risk of breast cancer was observed among postmenopausal Asian 462 Val allele carriers, including Japanese $(\mathrm{OR}=0.66 ; 95 \% \mathrm{CI}=0.45-0.96)$ (Miyoshi et al., 2002), North Indian (OR=0.33; 95\% $\mathrm{CI}=0.12-0.89$ ) (Singh et al., 2007) Chinese women who are homozygous for both CYPIAl M1 and M2 variant alleles $(\mathrm{OR}=0.43 ; 95 \mathrm{CI}=0.19$ - 0.99) (Boyapati et al., 2005), and, finally, Korean women only when the $M 1$ and $M 2$ variant alleles were combined together (OR $=0.59 ; 95 \% \mathrm{CI}=0.43-0.80)$ (Shin et al., 2007). On the contrary, a significant increased risk of breast cancer was observed among Caucasian women with at least one $462 \mathrm{Val}$ variant allele $(\mathrm{OR}=3.6 ; 95 \% \mathrm{CI}=1.5-8.2)$ (Zhang et al., 2004), among Asian women in North India $(\mathrm{OR}=2.08 ; 95 \% \mathrm{CI}=1.45-3.03)$ (Surekha et al., 2009) and 
in South Indian premenopausal women $(\mathrm{OR}=3.7 ; 95 \%$ $\mathrm{CI}=1.5-9.1)$ (Chacko et al., 2005). A recent meta-analysis has also found that the $462 \mathrm{Val}$ allele increases the risk of breast cancer among homozygous Caucasian participants (Sergentanis and Economopoulos, 2009).

When taking smoking into account, no association between the CYP1A1M2 and M4 polymorphisms and breast cancer risk was observed in either smokers or non-smokers, being consistent with the findings from the other studies among Caucasian women (Krajinovic, et al., 2001; Li et al., 2004) . However, among other Caucasian populations, a significant association between the breast cancer risk and CYP1A1 M2 (Ambrosone et al., 1995 ) and $M 1$ polymorphisms has been observed among smokers compared to non-smokers (Ishibe et al., 1998; Li et al., 2004)

Mild to moderate linkage disequilibrium between the CYP1A1 M1,M2 and M4 variants has been reported (D': 0.19-0.37) (PMID: 24772967). Our haplotype analysis revealed strong linkage disequilibrium for the two SNPs (M2 and M4). Very few studies evaluated haplotypes of CYPlAl in relation to breast cancer risk. Haplotype analysis of the two loci showed that the CA haplotype was associated with lowest risk of breast cancer among Korean women (Shin et al., 2007). In a study that was conducted in USA there was the suggestion of a difference in breast cancer risk by race in relation to the $C Y P 1 A l$ haplotype. However, the relation did not remain significant after adjustment for multiple testing (Reding, et al., 2012). In the current study, there were no significant differences in haplotype frequencies between controls and breast cancer cases.

The discrepancies in association of CYP1A1M2 or $M 4$ variant genotypes and breast cancer risk in different studies may be explained by several factors including ethnic differences in the frequency of the genetic polymorphism, diet, environmental exposure and number of subjects included in each study.

In summary, there is no overall association between CYPIAI M2 and M4 polymorphisms and breast cancer among Jordanian females, even after stratifying participants by menopausal status or smoking habits. Additional studies involving larger number of participants are needed to confirm or refute these findings.

Acknowledgment: The authors would like to thank the patients, control subjects as well as physicians, clinical staff for their collaboration. Special acknowledgment to Dr. Said Ismail and all JU molecular biology laboratory team for their collaboration and help. This study was supported by unconditional grant from the Deanship of Scientific Research (Jordan University, Jordan). The study sponsors had no part in the study design, data collection, data analysis, data interpretations or in the writing of the manuscript. The sponsors had no role in the decision to submit the paper for publication.

\section{References}

Ambrosone CB, Freudenheim JL, Graham S, et al (1995). Cytochrome P4501A1 and glutathione S-transferase (MI) genetic polymorphisms and postmenopausal breast cancer risk. Cancer Res, 55, 3483-5.

Bailey LR, Roodi N, Verrier CS, et al (1998). Breast cancer and CYPIA1, GSTM1, and GSTT1 polymorphisms: evidence of a lack of association in Caucasians and African Americans. Cancer Res, 58, 65-70.

Basham VM,Pharoah PD, Healey CS, et al (2001). Polymorphisms in CYP1A1 and smoking: no association with breast cancer risk. Carcinogenesis, 22, 1797-800.

Boyapati SM, Shu XO, Gao YT, et al (2005). Polymorphisms in CYP1Al and breast carcinoma risk in a population-based case-control study of Chinese women. Cancer, 103, 2228-35.

Cascorbi I, Brockmoller J, Roots I (1996). A C4887 A polymorphism in exon 7 of human CYP1A1: Population frequency, mutation linkages, and impact on lung cancer susceptibility. Cancer Res, 56, 4965-69.

Cavalieri N, Rogan E, Sinha D (1988). Carcinogenicity of aromatic hydrocarbons directly applied to rat mammary gland. J Cancer Res ClinOncol, 114, 3-9.

Chacko P, Joseph T, Mathew BS, et al (2005). Role of xenobiotic metabolizing gene polymorphisms in breast cancer susceptibility and treatment outcome. MutatRes, 581,153-63.

Clemons M, Goss P (2001). Estrogen and the risk of breast cancer. $N$ Engl J Med, 344, 276-85.

Cosma G, Crofts F, Taioli E, et al (1993). Relationship between genotype and function of the human CYPlAl gene.J Toxicol Environ Health, 40, 309-16.

Crofts F, Taioli E, Trachman J, et al (1994). Functional significance of different human CYP1Al genotypes. Carcinogenesis, 15, 2961-3.

Firozi PF, Bondy ML, Sahin AA, et al (2002). Aromatic DNA adducts and polymorphisms of CYP1A1,NAT2, and GSTM1 in breast cancer. Carcinogenesis, 23, 301- 6.

Giri SK, Yadav A, Kumar A, et al (2012). CYP1Al gene polymorphisms: modulator of genetic damage in coal-tar workers. Asian Pac J Cancer Prev, 13, 3409-16.

Hefler LA, Tempfer CB, Grimm C, et al (2004). Estrogenmetabolizing gene polymorphisms in the assessment of breast carcinoma risk and fibroadenoma risk in Caucasian women. Cancer, 101, 264-9.

Henkler F, Stolpmann K, Luch A (2012). Exposure to polycyclic aromatic hydrocarbons: bulky DNA adducts and cellular responses. EXS, 101, 107-31.

Hodek P, Koblihová J, Kizek R, et al (2013). The relationship between DNA adduct formation by benzo[a]pyrene and expression of its activation enzyme cytochrome P450 1A1 in rat. Environ Toxicol Pharmacol, 36, 989-96

Huang CS, Shen CY, Chang KJ, et al (1999). Cytochrome P4501 A1 polymorphism as a susceptibility factor for breast cancer in postmenopausal Chinese women in Taiwan. $\mathrm{Br} \mathrm{J}$ Cancer, 80, 1838-43.

Huo D, Zheng Y, Ogundiran TO, et al (2012). Evaluation of 19 susceptibility loci of breast cancer in women of African ancestry. Carcinogenesis, 33, 835-40

Ishibe N, Hankinson SE, Colditz GA, et al (1998). Cigarette smoking, cytochrome P450 1A1 polymorphisms, and breast cancer risk in the nurses' health study. Cancer Res, 58, 667-71.

Kawajiri K, Watanabe J, Gotoh O, et al (1986). Structure and drug inducibility of the human cytochrome P-450c gene. Eur J Biochem, 159, 219-25.

Kiruthiga PV, Kannan MR, Saraswathi C, et al (2011). CYP1A1 gene polymorphisms: lack of association with breast cancer susceptibility in the southern region (Madurai) of India. Asian Pac J Cancer Prev, 12, 2133-8.

Kiyohara C, Hirohata T, Inutsuka S (1996). The relationship between aryl hydrocarbon hydroxylase and polymorphisms of the CYP1A1 gene. Jpn J Cancer Res, 87, 18-24. 
Lack of Association between CYP1A1 M2 and M4 Polymorphisms and Breast Carcinoma in Jordanian Women: a Case-Control

Krajinovic M, Ghadirian P, Richer C, et al (2001). Genetic susceptibility to breast cancer in French-Canadians: role of carcinogen-metabolizing enzymes and gene-environment interactions. Int J Cancer, 92, 220-5.

Le Marchand L, Donlon T, Kolonel L, et al (2005). Estrogen Metabolism-related Genes and Breast Cancer Risk: the Multiethnic Cohort Study. Cancer Epidemiol Biomarkers Prev, 14, 1998-2003.

Li Y, Millikan R, Bell D, et al (2004). Cigarette smoking, cytochrome P4501A1 polymorphisms, and breast cancer among African-American and white women. Breast Cancer Res, 6, 460-73.

Martinez-Ramirez OC, Perez-Morales R, Castro C, et al (2013). Polymorphisms of catechol estrogens metabolism pathway genes and breast cancer risk in Mexican women. Breast, 22, 335-43.

Miyoshi Y, Takahashi Y, Egawa C, Noguchi S (2002). Breast cancer risk associated with $C Y P 1 A 1$ genetic polymorphisms in Japanese women. Breast $J, \mathbf{8}, 209-15$.

Mrozikiewicz PM, Cascorbi I, Brockmoller J, Roots I (1997). CYP1A1 mutations 4887A, 4889G, 5639C and $6235 \mathrm{C}$ in the Polish population and their allelic linkage, determined by peptide nucleic acid-mediated PCR clamping. Pharmacogenetics, 7, 303-7.

Persson I, Johansson I, Ingelman-Sundberg M (1997). In vitro kinetics of two human CYP1Al variant enzymes suggested tobe associated with interindividual differences in cancer susceptibility. Biochem Biophys Res Commun, 231, 227- 30.

Petchkovskiy EV, Shadrina AS, Boyarskih UA, et al (2014). The polymorphism of genes of synthesis and metabolism of estrogens and the risk of breast cancer. Klin Lab Diagn, 2, 19-23.

Rebbeck TR, Rosvold EA, Duggan DJ, et al (1994). Genetics of CYP1A1: coamplification of specific alleles by polymerase chain reaction and association with breast cancer. Cancer Epidemiol Biomarkers Prev, 3, 511-4.

Reding KW, Chen C, Lowe K, et al (2012). Estrogen-related genes and their contribution to racial differences in breast cancer risk. Cancer Causes Control, 23, 671-81.

Saadatian H, Gharesouran J, Montazeri V, et al (2014). Polymorphism of the cytochrome P-450 1A1 (A2455G) in women with breast cancer in Eastern Azerbaijan, Iran. Iran J Basic Med Sci, 17, 227-30.

Sergentanis T, Economopoulos K (2009). Four polymorphisms in cytochrome P450 1A1 (CYP1A1) gene and breast cancer risk: a meta-analysis. Breast Cancer ResTreat, 122, 459-69.

Shimada T, Fujii-Kuriyama Y (2004). Metabolic activation of polycyclic aromatic hydrocarbons to carcinogens by cytochromes P450 1A1 and 1B1. Cancer Sci, 95, 1-6.

Shin A, Kang D, Choi JY, et al (2007). Cytochrome P450 1A1 (CYP1A1) polymorphisms and breast cancer risk in Korean women. ExpMol Med, 39, 361-6.

Sillanpaa P. Heikinheimo L, Kataja V, et al (2007). CYP1A1 and CYP1B1 genetic polymorphisms, smoking and breast cancer risk in a Finnish Caucasian population. Breast Cancer Res Treat, 104, 287-97.

Singh V, Rastogi N, Sinha A, et al (2007). A study on the association of cytochrome-P450 1A1 polymorphism and breast cancer risk in north Indian women. Breast Cancer Res Treat, 101, 73-81.

Spink DC, Eugster HP, Lincoln DW, et al (1992). 17 $\beta$-Estradiol hydroxylation catalyzed by human cytochrome P450 1A1: a comparison of the activities induced by 2,3,7,8-tetrachlorodibenzo-p-dioxin in MCF-7 cells with those from heterologous expression of the cDNA. Arch Biochem. Biophys, 293, 342-8.

Stuckey B (2011). Breast Cancer: Epidemiology and Risk
Factors. Clin ObstetGynecol, 54, 96-102.

Sun MY, Du HY, Zhu AN (2015). Genetic Polymorphisms in Estrogen-Related Genes and the Risk of Breast Cancer among Han Chinese Women. Int J Mol Sci, 16, 4121-35.

Surekha D, Sailaja K, Rao D, et al (2009). Association of CYP1A1*2 polymorphisms with breast cancer risk: a case control study. Indian J Med Sci, 63, 13-20.

Tarawneh M, Nimri O, Arkoob K, Al Zaghal M (2010). Cancer incidence in jordan 2010. the hashemite kingdom of jordan, ministry of health, non-communicable diseases directorate, jordan cancer registry. [online].

Tsuchiya Y, Nakajima M, Yokoi T (2005). Cytochrome P450mediated metabolism of estrogens and its regulation in human. Cancer Lett, 227, 115-24.

Tworoger SS, Zhang X, Eliassen AH, et al (2014). Inclusion of endogenous hormone levels in risk prediction models of postmenopausal breast cancer. J Clin Oncol, 32, 3111-7

Weber BL, Nathanson KL (2000). Low penetrance genes associated with increased risk for breast cancer. Eur $J$ Cancer, 36, 1193-9.

Zhang B, Beeghly-Fadiel A, Long J, et al (2011). Genetic variants associated with breast cancer risk: comprehensive field synopsis, meta-analysis, and epidemiologic evidence. Lancet Oncol, 12, 477-88.

Zhang Y, Wise JP, Holford TR, et al (2004). Serum polychlorinatedbiphenyls, cytochrome P-450 1Alpolymorphisms, and risk of breast cancer in Connecticut women. Am J Epidemiol, 160, 1177-83.

Zhang Z, Fasco M, Huang L, et al (1996). Characterization of purified human recombinant cytochrome P4501A1-Ile462 and -Val462: assessment of a role for the rare allele in carcinogenesis. Cancer Res, 56, 3926-33.

Zhu BT, Conney AH (1998). Is 2-methoxyestradiol an endogenous estrogen metabolite that inhibits mammary carcinogenesis? Cancer Res, 58, 2269-77. 